\title{
Space station threat to science spending
}

AN enormous share of the US National Aeronautics and Space Administration (NASA)'s space science budget may wind up supporting the space station, according to some initial assessments by scientists advising the agency. Peter Banks of Stanford University, chairman of a panel said last week that $\$ 400-600$ million a year might be spent by "code E" NASAspeak for its science budget - on space station projects. The NASA science budget is now $\$ 1,404$ million, which goes to support both basic research, mainly at universities, and such major projects as the space telescope and the Venus Radar Mapper mission.

The space station programme, which received official presidential approval last January, will not be able to purchase scientific instruments or support research and analysis activities with the $\$ 8,000$ million tententatively approved for the project. All of these expenses with presumably be borne by code E. NASA officials say that $\$ 8,000$ million will buy a basic manned module, two accompanying unmanned platforms, and an orbiting manoeuvrable vehicle to transfer payloads from the station orbit to higher orbits.

Some scientists, particularly those interested in Earth observation experiments, say that a single polar platform cannot be large or flexible enough to meet their needs, which means that the potential cost savings from sharing power supplies and communications equipment on the space station platforms will not be realized by the science budget. NASA appears to be resisting suggestions that a flotilla of small platforms be built in place of the large platform. looking into scientific uses of the station,

NASA has just sent out its request for

proposals for initial design studies of the station, and the specifications include the two large platforms. Contractors for the initial design work will be chosen on 1 April next year. (John Hodge of the space station programme told Banks's committee this summer that the large platforms provided a more "unified" approach to the programme and would be well suited for commercial projects, such as manufacturing in space.)

Despite such concern, space scientists are reluctant to criticize NASA's space station plans. The frequently heard argument is that, because the space station is going to be built in any event, the best thing scientists can now do is to offer their full support. In that way, they can hope to influence some design details to ensure that some good science can be carried out.

Burton Edelson, director of the Office of Space Science and Applications, told the Space and Earth Sciences Advisory Committee last week that, because his office had been "supportive" of the space station over the years, it had already been able to make the project "more suitable" for science. He said there would not have been unmanned platforms at all if it were not for his office's advocacy.

At the same time, some say that there are great political pressures on the NASA science programmes to make use of the space station, which is seen by many as long on engineering and short on purpose. The same reservations were expressed, to a lesser degree, about the role of science in the shuttle programme. The Office of Space Science and Applications is spending 13 per cent of its current budget on shuttle projects.

The Banks committee, significantly, was not asked to decide whether scientific

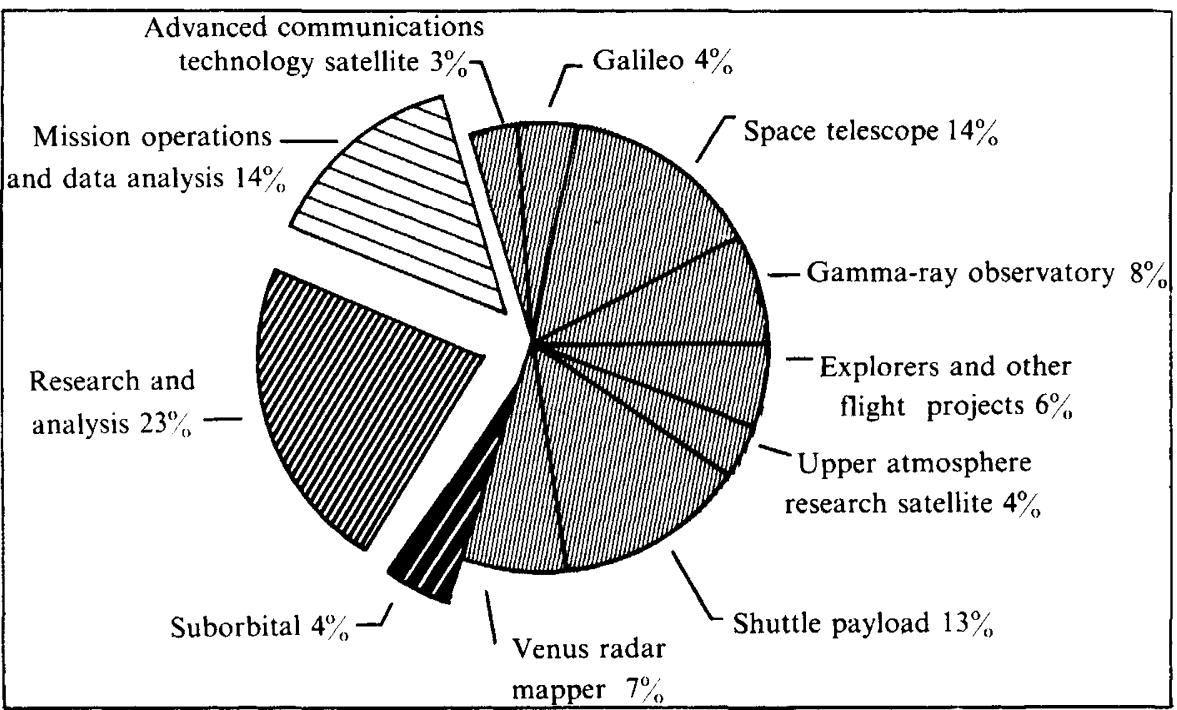

activities could better be carried on the station, but only what activities could be carried out on it. It seems agreed that the space station opens up some new possibilities but most of the experiments listed by Banks's committee, and by the Space Science Board in a separate study, could clearly be done as well if not better without the station.

Some relief for the science budget may come from abroad. NASA administrator James Beggs has been pushing hard for Japanese and European contributions to the cost, to the tune of $\$ 1,000$ million and $\$ 2,000$ million respectively. There is some talk of the foreign contributions going for a second polar platform.

Stephen Budiansky

\section{ESR to Gronoble in} Franco-German deal

\section{Paris}

OfFicials representing Hubert Curien and Heinz Riesenhuber, the French and German science ministers, last week had to answer for the Franco-German decision to site the European Synchrotron Radiation Source (ESRS) at Grenoble.

On Friday in Brussels, they met their opposite numbers from the smaller European states under the auspices of the European Science Foundation (ESF) " progress committee" which - according at least to Denmark and Italy - had been gathering and evaluating site proposals. Instead, the committee was faced with a decision by France and Germany that ESRS should be built in Grenoble.

In fact, the first notice other governments had of the "decision" - except for press reports - came in a joint letter from Curien and Riesenhuber only on Tuesday last week, too late for official reactions by Friday. What may now emerge is an agreement between France, Germany, Britain and Italy to which the smaller states, notably those of Scandinavia, might adhere in a separate consortium. But Denmark, clearly the most hurt is unwilling to participate. The Netherlands is also playing cool.

Meanwhile, Britain, which France and Germany dearly want as a partner, while strongly backing the Grenoble site, has no money to offer, and may enter only with observer status "or something between that and full participation'. The French certainly are not keen to see ESRS start up as a purely Franco-German institute, as the Institut Laue-Langevin was before 1967.

And why did France and Germany (and in effect the United Kingdom) ignore the ESF progress committee? Because it had too low a political level, say French sources, and would have been unable to trade one facility for another. This, finally, is what France and Germany did with ESRS and the trans-sonic wind tunnel, now to be built at Cologne. Robert Walgate 